\title{
Mineralogia e geoquímica dos perfis sobre sedimentos neógenos e quaternários da bacia do Solimões na região de Coari - AM
}

\author{
Adriana Maria Coimbra HORBE${ }^{1}$, Mara Rúbia Pereira de PAIVA², Marcelo Batista MOTTA ${ }^{1}$ e Marco \\ Antonio $\mathrm{HORBE}^{3}$
}

\begin{abstract}
RESUMO
O estudo do intemperismo das rochas é uma ferramenta indispensável para entender a evolução paleoambiental do Cenozóico na Amazônia. Com esse objetivo foram estudados seis perfis intempéricos desenvolvidos a partir da Formação Solimões e um perfil do Quaternário da várzea do rio Solimões, no centro-leste do estado do Amazonas. As informações obtidas permitiram determinar o grau de evolução intempérica na regiāo, além das suas características estruturais, mineralógicas e químicas. Os perfis desenvolvidos sobre a Formação Solimões são constituídos, de baixo para cima, pelos horizontes saprolítico (C), mosqueado (B) e solo (A), enquanto o perfil sobre a sedimentação quaternária é estruturado nos horizontes saprolito (C) e solo (A). São argilo-arenosos a areno-argilosos, cinzentos, amarelados, avermelhados e esbranquiçados e compóem-se de quartzo, caulinita, muscovita, illita e esmectita. Segundo as suas características os perfis são divididos em dois grupos: 1) perfis 2, 3, 4 e 5: são areno-argilosos, tem altos teores de $\mathrm{SiO}_{2}, \mathrm{Hg}_{\mathrm{g}} \mathrm{Zr}$ e estão associados unicamente à Formação Solimões; 2) perfis 1, 6 e 7: são pelíticos, têm maiores conteúdos em esmectita, illita, muscovita, $\mathrm{Al}_{2} \mathrm{O}_{3}$, álcalis e elementos-traço, especialmente de $\mathrm{Ba}, \mathrm{Co}, \mathrm{Li}, \mathrm{Ni}, \mathrm{Sr}, \mathrm{V}, \mathrm{Y}$ e $\mathrm{Zn}$, e agrupam parte dos perfis sobre a Formação Solimões e o sedimento quaternário. A semelhança geoquímica entre este último e parte dos perfis sobre a Formação Solimões sugere que esta pode ser a fonte pelo menos de parte do material depositado na várzea. O conjunto das características demonstra que os horizontes dentro de cada perfil são muito semelhantes entre si e, portanto, pouco evoluídos, apesar do clima atual quente e chuvoso da regiāo de Coari $\left(2300 \mathrm{~mm} . \mathrm{ano}^{-1}\right)$ promover intensa lixiviação. Conseqüentemente, por serem derivados dos sedimentos mais jovens da Bacia do Solimões, e, portanto sob ação recente do intemperismo, pode-se afirmar que a unidade que deu origem aos perfis na Formação Solimões foi exposta no Quaternário e que estes se encontram em desequilíbrio com as condiçôes agressivas de lixiviação do ambiente laterítico reinantes na Amazônia pelo menos desde o Paleógeno.
\end{abstract}

\section{PALAVRAS-CHAVE}

Neossols, formação do Solimões, lateritização.

\section{Mineralogy and geochemistry of Neogene and Quaternary sediment profiles from the Solimoes Basin in the region of Coari, Amazonas}

\begin{abstract}
To shed light on lateritic evolution, six profiles were studied of weathered sediment developed on the Solimões Formation and one profile on Quaternary floodplain deposits of the Solimōes River within the Solimöes basin in the center-east of Amazonas State. The profiles on the Solimões Formation are comprised upwards of saprolitic (C), mottled $(B)$ and soil (A) horizons, while the profile on the Quaternary floodplain sediments has only the saprolitic (C) and soil (A) horizons. All profiles are clayey-sands to sandy-clays, grey, yellowish, reddish or whitish and predominantly composed of quartz, kaolinite, muscovite, illite and smectite. Based on their textural, mineralogical, and chemical characteristics, the profiles are divided into two groups. Profiles 2, 3, 4 and 5 are sandy-clays, have high contents of SiO, $\mathrm{Hg}$ and $Z r$ and are only associated with the Solimôes Formation; Profiles 1, 6 and 7 are pelitic, have higher contents of smectite, illite and muscovite, $\mathrm{Al}_{2} \mathrm{O}_{3}$, alkalis and trace-elements, especially $\mathrm{Ba}, \mathrm{Co}, \mathrm{Li}, \mathrm{Ni}, \mathrm{Sr}, \mathrm{V}, \mathrm{Y}$ and $\mathrm{Zn}$, and are found on both the Solimoes Formation and the Quaternary floodplain sediments. This suggests that the Solimoes Formation was the source for some of the Quaternary floodplain sediments in the region. The set of mineralogical and chemical characteristics indicates a similarity between horizons within each profile. The profiles on the Solimöes Formation are not highly weathered, despite the hot and rainy climate prevailing in the Coari region (2300 mm.year ${ }^{-1}$ ), which would favor intense leaching. Therefore the studied profiles are in disequilibrium with the lateritic environment in Amazonia.
\end{abstract}

KEY-WORDS

Neossolos, Solimôes Formation, lateritization.

${ }^{1}$ Universidade Federal do Amazonas, Departamento de Geociências. Avenida General Rodrigo Otávio Jordão Ramos, 3000-Japiim. CEP: 69077-000 Manaus, AM e-mail: ahorbe@ufam.edu.br ${ }^{2}$ Autônoma

${ }^{3}$ Serviço Geológico do Brasil. Avenida André Araújo 2160, Aleixo, 69060-001, Manaus-AM. 


\section{INTRODUÇÃO}

Na Amazônia predominam Latossolos e Argissolos associados ao topo de perfis lateríticos desenvolvidos sobre rochas intensamente intemperizadas em condiçōes de clima tropical sazonal quente e úmido (Costa, 1991; Truckenbrodt et al., 1991). Na Amazônia Ocidental as Formações Alter do Chão, PA e Novo Remanso são as unidades mais recentes da Bacia do Amazonas afetadas pela lateritização (Fernandes Filho et al., 1996; Horbe et al., 2001; Horbe et al. 2005). Perfis dessas unidades ocorrem ao longo do quase todo o rio Amazonas até um pouco a oeste da confluência do Solimôes com o Negro (Figura 1). O rio Solimōes ocorre encaixado em rochas sedimentares da Formação Solimões da bacia homônima, bem como em depósitos quaternários que formam a várzea desse rio (Nogueira et al., 2003; Rossetti et al., 2005). Há poucos trabalhos sobre as características desses sedimentos (Konhauser et al., 1994; Kronberg et al., 1998; Rossetti et al., 2005) e sobre os perfis resultantes de seu intemperismo e não há relatos da presença de

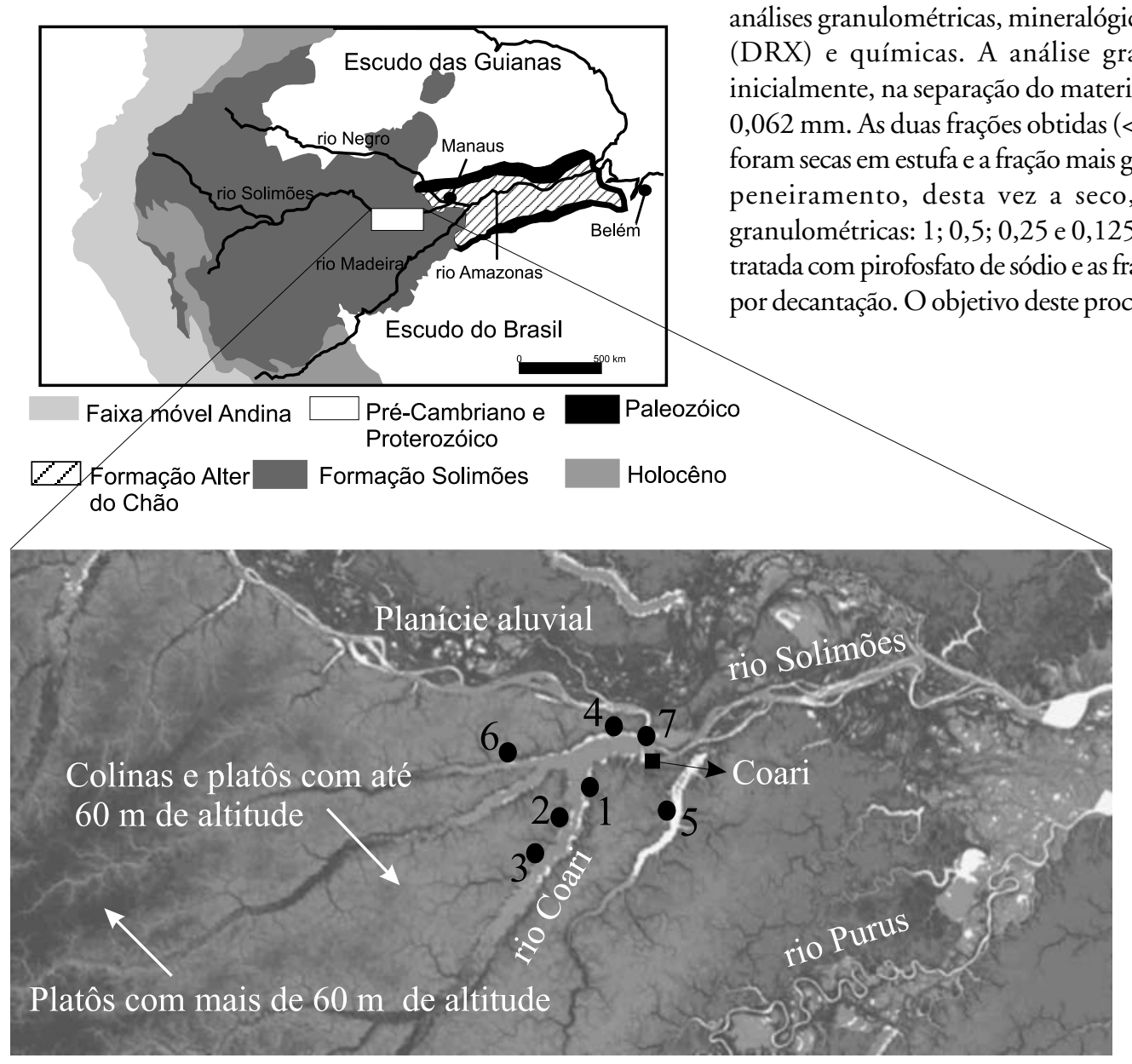

crostas lateríticas (Rosolen et al., 2002; Radambrasil, 1978) o que indica que o intemperismo na Amazônia Ocidental foi pouco expressivo. Portanto, este trabalho tem por objetivo a caracterização geoquímica dos perfis da Formação Solimōes e dos sedimentos quaternários que formam as escarpas do rio Solimōes, na regiāo centro-leste da Bacia do Solimôes (Figura 1), com vistas a contribuir no estudo das transformaçôes dos sedimentos Neógenos e Quaternários sob as condições climáticas quentes e úmidas reinantes na região.

\section{MATERIAL E MÉTODOS}

Foram selecionados 7 perfis para este estudo, localizados ao longo das principais drenagens da área, dos quais 6 se desenvolveram a partir da Formação Solimões (lago de Coariperfis 1, 2, 3 e 4; lago Mamiá - perfil 5; lago Urucu - perfil 6) e um a partir dos sedimentos quaternários da várzea do rio Solimões (perfil 7).

Após a coleta, as amostras foram secas e descritas, com ênfase nas características texturais e de cor. Em seguida, foram feitas análises granulométricas, mineralógicas via difração por raios- $\mathrm{x}$ (DRX) e químicas. A análise granulométrica consistiu, inicialmente, na separação do material pelítico com peneira de $0,062 \mathrm{~mm}$. As duas frações obtidas $(<0,062 \mathrm{~mm}$ e $>0,062 \mathrm{~mm})$ foram secas em estufa e a fração mais grossa foi submetida a novo peneiramento, desta vez a seco, nas seguintes malhas granulométricas: 1; 0,5; 0,25 e 0,125 mm. A fração pelítica foi tratada com pirofosfato de sódio e as fraçôes silte e argila separadas por decantação. O objetivo deste procedimento foi identificar os

Figura 1- Mapa geológico e de localização da área de estudo 
argilominerais com base nos difratogramas de raios-x em condiçōes naturais com os submetidos à adsorção de etilenoglicol e aquecidos a $500^{\circ} \mathrm{C}$ por 5 horas. As análises de DRX foram realizadas em equipamento Shimadzu XRD 6000, equipado com anodo de $\mathrm{Cu}$, e com intervalo de leitura entre $5^{\circ}$ a $60^{\circ} 2 \grave{\text { è }}$

As análises químicas para os óxidos maiores totais foram feitas via abertura ácida e fusão alcalina em todas as amostras. Por fusão, foram determinados, por gravimetria, $\mathrm{SiO}_{2}$; por calcinação, $\mathrm{PF}$ (perda ao fogo); por titulação, $\mathrm{Al}_{2} \mathrm{O}_{3}$ e C orgânico; por colorimetria, $\mathrm{Fe}_{2} \mathrm{O}_{3}, \mathrm{TiO}_{2} \mathrm{eP}_{2} \mathrm{O}_{5}$. Na soluçâao ácida foram dosados, por espectrometria de absorção atômica, $\mathrm{Na}_{2} \mathrm{O}, \mathrm{K}_{2} \mathrm{O}, \mathrm{CaO}$ e $\mathrm{MgO}$. Os elementos trocáveis foram analisados nos perfis 4 (sobre a Formação Solimões) e 7 (sobre o sedimento quaternário), que representam aqueles onde a variação dos teores de álcalis é mais elevada. Foram obtidos por extração com $\mathrm{KCl} 1 \mathrm{M}(\mathrm{Ca}, \mathrm{Mg}$ e Al) e com $\mathrm{HCl} 0,05 \mathrm{M} \mathrm{e} \mathrm{H}_{2} \mathrm{SO}_{4} 0,0125 \mathrm{M}$ (P, Ke Na). Todas essas análises descritas foram realizadas nos laboratórios do Departamento de Geociências da Universidade Federal do Amazonas. Os elementos traços $\mathrm{Cu}, \mathrm{Pb}, \mathrm{Zn}, \mathrm{Zr}, \mathrm{Ni}, \mathrm{Co}, \mathrm{Cr}, \mathrm{B}$, $\mathrm{Ba}, \mathrm{Be}, \mathrm{Bi}, \mathrm{Cd}, \mathrm{Li}, \mathrm{Mo}, \mathrm{Sc}, \mathrm{Sr}, \mathrm{Sn}, \mathrm{V}, \mathrm{W}$ e Y foram analisados por plasma de indução acoplada; $\mathrm{Ag}$, As e Sb por absorção atômica, sendo os dois últimos com geração de hidretos, todos na Lakefield Geosol Ltd em Belo Horizonte. O Hg foi analisado também por absorção atômica a partir da geração de vapor frio nos laboratórios do Instituto Evandro Chagas - FUNASA, em Belém do Pará.

A diferenciação geoquímica dos perfis foi definida por análise de componentes principais com o programa Statistica 5.1. Esse método permite determinar as correlações entre os dados (variáveis) que são expressas em fatores. Cada fator é representado por valores que informam as cargas de correlação entre as variáveis. Para a expressão dessas cargas utilizou-se um diagrama XY.

\section{GEOLOGIA E ASPECTOS FISIOGRÁFICOS}

A bacia do rio Solimões, localizada na porção central do Estado do Amazonas, entre os arcos de Iquitos e Purus, foi, atéo Mioceno, palco de sedimentação que culminou com a deposição da Formação Solimões. No Neógeno, com a consolidaçẫo da cadeia andina, houve inversão da drenagem de oeste para leste, com o estabelecimento da atual bacia do rio Solimōes (Hooghiemstra \& Hammen, 1998), e ao longo do seu curso, em conseqüência dos seus meandros e da grande quantidade de material carreado em suspensão, houve deposiçãao de sedimentos quaternários.

Apesar de Rossetti et al. (2005) considerar os sedimentos desta região como depósitos quaternários, é a Formação Solimões que ocorre ao longo das escarpas mais altas de parte dos rios Solimões, Coari e Purus (Figura 2). Esta é constituída por argilitos friáveis cinza a cinza esverdeados, com finas intercalaçôes de areia, tendendo a ser mais arenoso no topo. Recobrindo esta unidade ocorre a Formação Içá, que também é constituída de sedimentos arenosos inconsolidados de coloração esbranquiçadas e argilitos cinza a amarelados (Maia, 1977; Radambrasil, 1978). A sedimentação quaternária configura os depósitos arenosos e argilosos das várzeas e ilhas do rio Solimões, também forma escarpas, porém de menor altura. Na Formação Solimōes e nos depósitos quaternários, é comum a presença de matéria orgânica, como restos de folhas e troncos.

Os perfis da Formação Solimões estudados se encaixam na unidade geomorfológica de colinas e platôs rebaixados com até $60 \mathrm{~m}$ de altitude, enquanto o do Quaternário faz parte da planície aluvial atual do rio Solimões (Figura 1). A regiāo de Coari é caracterizada pela ausência de período seco no ano e por chuvas mais intensas entre dezembro e maio, com totais anuais da ordem de $2300 \mathrm{~mm}$ e temperatura média de $26^{\circ} \mathrm{C}$. A cobertura vegetal é do tipo floresta tropical densa. A malha hidrográfica da área é formada pelos rios Coari e seus afluentes, o Urucu e o Arauá, que deságuam na margem direita do rio Solimões, onde está localizada a cidade de Coari; e pelo rio Mamiá, cuja confluência com o Solimões ocorre mais à jusante (Figura 1). Esses rios menores formam lagos tipo ria.

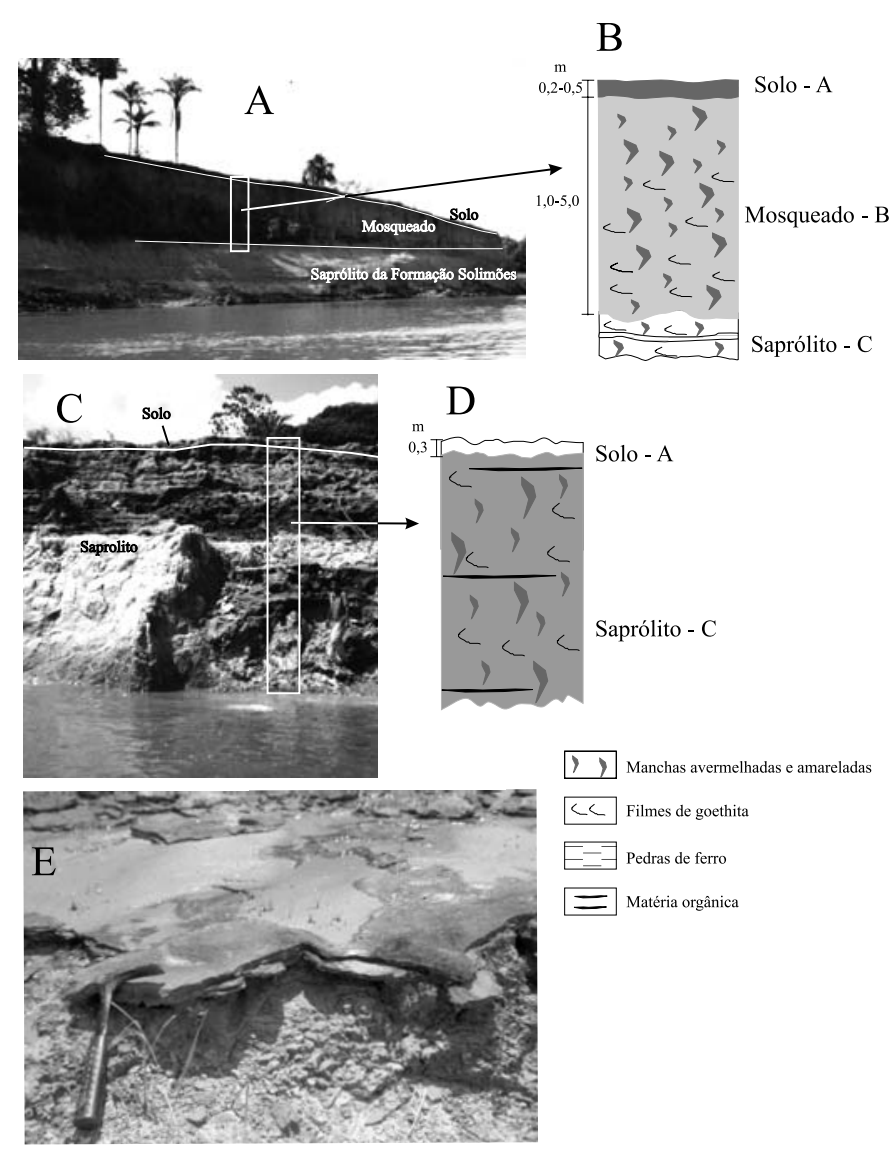

Figura 2 - Escarpa no rio Solimões (A), perfil esquemático desenvolvido sobre da Formação Solimões no rio hômonimo (B), escarpa (C) e perfil esquemático do Neossolo (D); pedras de ferro no saprólito da Formação Solimões (D). 


\section{CARACTERÍSTICAS DOS PERFIS}

Nas escarpas dos rios percorridos ocorrem as melhores exposiçōes dos perfis (Figura 2). Estas apresentam até $15 \mathrm{~m}$ de altura nos desenvolvidos sobre a Formação Solimões, mas os sedimentos desta unidade nem sempre estão expostos, pois, muitas vezes, ocorrem feiçõos de escorregamento o que dificulta a observação de perfis completos. Os perfis estão estruturados, de baixo para cima, nos horizontes da rocha-mãe (Formação Solimōes), saprólito, mosqueado e solo (Figura 2B). O saprólito, genericamente correlato ao horizonte $\mathrm{C}$ dos perfis de solo, é argiloarenoso a areno-argiloso, tem coloração cinza clara a amarelada e, em geral, exibe abundantes manchas de cores amareladas a avermelhadas, produto do acúmulo de óxi-hidróxidos de ferro, com dimensōes que variam de $5 \mathrm{~mm}$ a $15 \mathrm{~mm}$. Ocorrem filmes de goethita recobrindo os canais de percolação de água o que indica intensa migração de ferro. Neste horizonte também são comuns as pedras de ferro (iron stone) constituídas por goethita e, subordinadamente, hematita, que cimentam grãos de quartzo de até $2 \mathrm{~mm}$ de diâmetro (Figura 2E). Formam placas sinuosas com 1 a $5 \mathrm{~cm}$ de espessura e ocorrem na zona de flutuação atual do nível de água subterrânea, no contato de zonas arenosas e argilosas com diferentes permeabilidades.

O horizonte mosqueado ou horizonte $\mathrm{B}$ mantém a textura areno-argilosa a argilo-arenosa do horizonte saprolítico, tem espessura de $1,0 \mathrm{~m}$ a 5,0 m. Tem estrutura maciça, apresenta coloração de cinza a laranja avermelhado com filmes marromamarelados de goethita e manchas mais avermelhadas e amareladas que o fundo matricial. Em relação ao saprólito, estas são mais intensas, mais abundantes e interligadas.

O solo ou horizonte $A$, com 0,2 a $0,5 \mathrm{~m}$ de espessura, tem textura similar ao horizonte mosqueado, mas exibe cor marrom a cinza escuro, é estruturado em blocos com prismas colunares a anisoformes, tendendo a microagregado no topo. Somente no perfil 6 foram encontrados nódulos ferruginosos, de 0,5 a $1 \mathrm{~cm}$ de diâmetro, caracterizando maior enriquecimento em ferro.

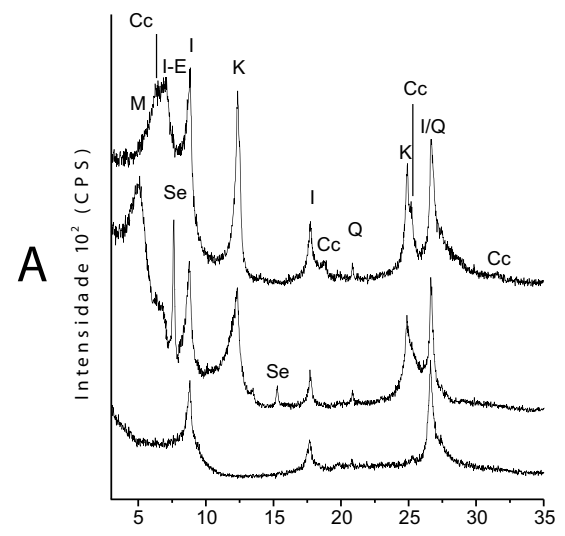

Os sedimentos quaternários que, preferencialmente, ocorrem nas várzeas do rio Solimões mostram incipiente estruturação de horizontes e são classificados como Neossolos Flúvicos (Figura 2B e C). O saprólito do perfil estudado, ou o horizonte C, é texturalmente argilo-arenoso, contém restos de matéria orgânica, tem coloração cinzenta com manchas amareladas e filmes de goethita formados pela percolação de água e é nítida a preservação da laminação da rocha-mãe. O horizonte de topo, ou $\mathrm{A}$, tem no máximo $0,30 \mathrm{~m}$ de espessura, constituição argilo-arenosa, friável, coloração cinza clara, localmente esbranquiçado.

\section{CARACTERISTIICAS GRANULOMÉTRICAS E MINERALÓGICAS}

Em quase todos os perfis predomina a fração pelítica $(<0,062$ $\mathrm{mm}$ ), que representa pelo menos $38 \%$ do material total. A areia fina $(0,25-0,125 \mathrm{~mm})$ a muito fina $(0,125-0,062 \mathrm{~mm})$ perfaz no máximo $52 \%$ no saprólito e $47 \%$ no solo. A areia grossa $(>1 \mathrm{~mm})$ representa menos que $1 \%$, exceto no saprólito de alguns perfis onde ocorrem pedras de ferro, neste caso, essa fração alcança $70 \%$ do material e é composta por fragmentos derivados do seu quebramento in situ. Dentre as fraçōes, a areia fina e a média são as que apresentam maior variação de proporção, entre 2 e $60 \%$ do material total, especialmente nos perfis 2 e 4 . Em apenas dois perfis a fração pelítica predomina no solo e no horizonte mosqueado, o que pode indicar provável corrosão/ dissolução do quartzo, contudo, devido a incipiente diferenciação entre os horizontes dos perfis, esse fato deve estar ligado a variação granulométrica herdada da rocha sedimentar. No Neossolo (perfil 7) a fração pelítica é a predominante (entre 60 e $97 \%$ ) seguida da areia fina com até $50 \%$, o horizonte de topo é composto basicamente de areia fina e pelito, em proporçōes similares.

Nos difratogramas de raios-X de amostra total de todos os perfis estudados, quartzo e caulinita são os minerais mais abundantes, seguidos de muscovita. Hematita, goethita e anatásio ocorrem em baixas proporçôes, pois apenas a reflexão de $100 \%$ desses minerais $(33,152-21,240-25,156$ о $2 \theta$, respectivamente) foi identificada. A presença de apatita é sugerida pelos teores de fósforo. Na fração argila foi identificada, além da caulinita, illita e montmorillonita, enquanto interestratificados

Figura 3 - A - Difratogramas de raios-x da fração argila na condição de seca ao ar, glicolada e aquecida (CC - clinocloro, M - motmorillonita, I - illita, K caulinita, Se - sepolita, I-E - interestratificado illita-esmectita, I/Q - illita e quartzo e Q - quartzo); B e C cristais de caulinita do saprólito. 
illita-esmectita, clinocloro, sepiolita e clorita-vermiculita estão restritos aos sedimentos da Formação Solimões (Figura 3A). Em condiçōes normais (seca ao ar), a caulinita apresentou reflexôes apenas em 12,21 e $24,99^{\circ} 2 \theta$, o que indica seu baixo ordenamento cristalográfico. A illita é identificada em 8,74; 17,72

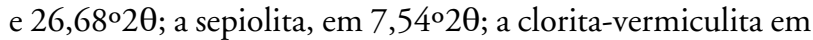
$6,32^{\circ} 2 \theta$; o clinocloro em $18,76^{\circ} 2 \theta$ e interestratificado em 6,42。2 $\theta$. A montmorillonita foi identificada após ser submetida à adsorção de etilenoglicol que descolou a sua reflexão entre $6^{\circ} \mathrm{e}$ $7 \circ 2 \theta$ coincidente com a do clinocloro e do interestratificado para $4.98^{\circ} 2 \theta$. Os demais argilominerais mantiveram suas reflexôes por não serem expansivos. Ao serem aquecidos a $550^{\circ} \mathrm{C}$, somente a illita manteve suas reflexões e os demais tiveram suas estruturas destruídas (Figura 3A). Nas análises de microscopia eletrônica de varredura (MEV) foi identificada somente caulinita, que ocorre na forma de cristais planares com bordas arredondadas, sugerindo origem detrítica (Figura 3 ).

\section{CARACTERÍSTICAS QUIIMICAS}

\section{ÓXIDOS MAIORES E MENORES}

Os resultados das análises químicas totais dos sete perfis estudados indicam conteúdos de $\mathrm{SiO}_{2}$ entre $42 \%$ e $79 \%$, como principal componente, especialmente nos perfis 2 , 4 e 5 , seguido de $\mathrm{Al}_{2} \mathrm{O}_{3}$ entre $1 \%$ e $27 \%$ (Tabela 1). $\mathrm{O} \mathrm{Fe}_{2} \mathrm{O}_{3}$ varia entre $2 \%$ e $10 \%$, exceto no saprólito do perfil 1 , onde perfaz $35 \%$ (Tabela 1 ), valor esse justificado pela intensa impregnação por ferro provocada pela presença de um nível de pedra de ferro nesse horizonte. A perda ao fogo (PF) varia entre $2 \%$ e $9 \%$, sendo geralmente mais elevada no saprólito o que é justificado pela

Tabela 1 - Composição química dos perfis estudados em \% em peso.

\begin{tabular}{|c|c|c|c|c|c|c|c|c|c|c|c|c|}
\hline Horizontes & $\mathrm{SiO}_{2}$ & $\mathrm{Al}_{2} \mathrm{O}_{3}$ & $\mathrm{Fe}_{2} \mathrm{O}_{3}$ & $\mathrm{PF}$ & $\mathrm{TiO}_{2}$ & $\mathrm{Na}_{2} \mathrm{O}$ & $\mathrm{K}_{2} \mathrm{O}$ & $\mathrm{CaO}$ & $\mathrm{MgO}$ & $\mathrm{P}_{2} \mathrm{O}_{5}$ & C orgânico & Total $^{*}$ \\
\hline \multicolumn{13}{|c|}{ Perfis sobre a Formação Solimões } \\
\hline \multicolumn{13}{|c|}{$\begin{array}{l}\text { Perfil } 1 \\
\end{array}$} \\
\hline Solo & 73,9 & 13,18 & 4,06 & 5,49 & 1,09 & 0,15 & 0,42 & 0,22 & 0,88 & 0,34 & 0,61 & 99,72 \\
\hline Mosqueado & 66,01 & 20,25 & 4,73 & 5,98 & 0,55 & 0,13 & 0,36 & 0,25 & 1,23 & 0,26 & 3,50 & 99,75 \\
\hline Mosqueado & 65,77 & 20,84 & 5,39 & 5,52 & 0,59 & 0,12 & 0,27 & 0,24 & 1,13 & 0,20 & 1,21 & 100,07 \\
\hline Saprólito & 67,01 & 17,89 & 3,84 & 6,44 & 0,37 & 0,81 & 1,56 & 0,23 & 1,05 & 0,23 & 4,90 & 99,43 \\
\hline Saprólito & 42,14 & 12,18 & 35,11 & 9,18 & 0,27 & 0,07 & 0,17 & 0,19 & 0,51 & 0,67 & 0,15 & 100,40 \\
\hline Solo & 79,15 & 11,28 & 3,22 & 5,49 & 0,89 & 0,07 & 0,08 & 0,01 & 0,17 & 0,63 & 3,40 & 100,99 \\
\hline Solo & 72,11 & 15,9 & 4,54 & 6,19 & 0,65 & 0,12 & 0,27 & 0,01 & 0,17 & 1,05 & 3,03 & 101,01 \\
\hline Solo & 72,13 & 16,8 & 4,41 & 5,65 & 0,60 & 0,07 & 0,16 & 0,02 & 0,17 & 0,66 & 3,22 & 100,67 \\
\hline Mosqueado & 7803 & 12,92 & 3,17 & 3,61 & 1,08 & 0,06 & 0,05 & 0,16 & 0,14 & 0,31 & 1,27 & 99,53 \\
\hline Mosqueado & 71,58 & 19,84 & 3,30 & 4,27 & 0,38 & 0,14 & 0,09 & 0,21 & 0,22 & 0,32 & 0,50 & 100,35 \\
\hline \multicolumn{13}{|c|}{ Perfil 3} \\
\hline Solo & 69,37 & 19,04 & 5,17 & 5,82 & 0,39 & 0,12 & 0,11 & 0,01 & 0,28 & 0,30 & 3,95 & 100,61 \\
\hline Saprolítico & 69,78 & 19,93 & 2,83 & 5,55 & 0,88 & 0,75 & 0,12 & 0,12 & 0,31 & 0,19 & 1,49 & 100,46 \\
\hline \multicolumn{13}{|c|}{ Perfil 4} \\
\hline Solo & 71,27 & 12,86 & 5,45 & 6,37 & 4,30 & 0,08 & 0,01 & 0,03 & 0,20 & 0,29 & 0,63 & 100,85 \\
\hline Solo & 73,24 & 15,38 & 3,10 & 5,74 & 0,54 & 0,08 & 0,06 & 0,03 & 0,21 & 1,15 & 0,88 & 99,53 \\
\hline Mosqueado & 75,77 & 14,15 & 2,45 & 4,84 & 0,49 & 0,09 & 0,05 & 0,01 & 0,26 & 0,84 & 0,54 & 98,95 \\
\hline Mosqueado & 73,07 & 16,06 & 3,48 & 4,84 & 0,99 & 0,09 & 0,06 & 0,06 & 0,28 & 0,62 & 0,75 & 99,55 \\
\hline Mosqueado & 74,26 & 17,48 & 2,30 & 3,94 & 0,40 & 0,08 & 0,11 & 0,06 & 0,22 & 0,72 & 0,54 & 99,57 \\
\hline Saprolítico & 73,23 & 19,62 & 2,37 & 3,22 & 1,11 & 0,06 & 0,03 & 0,06 & 0,15 & 0,50 & 1,53 & 100,35 \\
\hline \multicolumn{13}{|c|}{ Perfil 5} \\
\hline Solo & 75,81 & 17,43 & 2,11 & 5,37 & 0,31 & 0,15 & 0,10 & 0,08 & 0,19 & 0,46 & 3,30 & 101,55 \\
\hline Mosqueado & 75,64 & 18,79 & 3,67 & 2,04 & 0,27 & 0,08 & 0,09 & 0,01 & 0,11 & 0,40 & 8,80 & 100,70 \\
\hline Mosqueado & 72,50 & 19,30 & 2,27 & 5,23 & 0,30 & 0,11 & 0,14 & 0,03 & 0,17 & 0,40 & 0,84 & 100,05 \\
\hline \multicolumn{13}{|c|}{ Perfil 6} \\
\hline Solo & 60,25 & 23,29 & 9,59 & 6,81 & 0,35 & 0,08 & 0,14 & 0,01 & 0,36 & 1,02 & 1,49 & 101,90 \\
\hline Solo & 62,23 & 27,62 & 2,98 & 6,44 & 0,33 & 0,12 & 0,26 & 0,01 & 0,40 & 1,95 & 0,84 & 102,34 \\
\hline Saprolítico & 47,19 & 12,03 & 30,26 & 8,10 & 3,15 & 0,05 & 0,16 & 0,02 & 0,38 & 0,50 & 0,93 & 101,84 \\
\hline \multicolumn{13}{|c|}{ Perfil sobre 0 sedimento quaternário } \\
\hline \multicolumn{13}{|c|}{$\begin{array}{l}\text { Perfil } 7 \\
\end{array}$} \\
\hline Horizonte A & 62,08 & 24,66 & 6,45 & 5,27 & 0,34 & 0,09 & 0,32 & 0,4 & 1,59 & 1,99 & 1,53 & 103,19 \\
\hline A & 69,92 & 20,89 & 2,65 & 4,43 & 0,29 & 0,12 & 0,25 & 0,3 & 1,11 & 2,96 & 1,82 & 102,92 \\
\hline C & 61,96 & 24,38 & 6,45 & 5,73 & 0,33 & 0,13 & 0,33 & 0,24 & 1,18 & 1,18 & 0,33 & 101,91 \\
\hline C & 66,76 & 20,59 & 6,43 & 5,72 & 0,30 & 0,14 & 0,27 & 0,29 & 1,25 & 0,90 & 1,64 & 102,65 \\
\hline C & 63,99 & 21,16 & 4,67 & 7,73 & 0,28 & 0,11 & 0,22 & 0,22 & 0,56 & 2,82 & 0,08 & 101,76 \\
\hline
\end{tabular}




\begin{tabular}{|c|c|c|c|c|c|c|}
\hline Perfil/Horizontes & Al & $\mathrm{Na}$ & K & $\mathrm{Ca}$ & $\mathrm{Mg}$ & P \\
\hline \multicolumn{7}{|c|}{ Perfil 4} \\
\hline Solo & 1039 & 69 & 234 & 9 & 14 & 1 \\
\hline Solo & 947 & 69 & 219 & 6 & 7 & 0 \\
\hline Mosqueado & 847 & 69 & 1815 & 7 & 76 & 5 \\
\hline Mosqueado & 747 & 71 & 582 & 6 & 21 & 1 \\
\hline Mosqueado & 998 & 71 & 340 & 6 & 12 & 2 \\
\hline Saprólito & 378 & 69 & 302 & 11 & 13 & 0 \\
\hline Formação Solimões & 847 & 64 & 154 & 7 & 29 & 1 \\
\hline \multicolumn{7}{|c|}{ Perfil 7} \\
\hline A & 94 & 69 & 967 & 1106 & 954 & 5 \\
\hline A & 178 & 71 & 662 & 938 & 944 & 4 \\
\hline C & 278 & 69 & 482 & 1639 & 1093 & 3 \\
\hline C & 178 & 69 & 1245 & 889 & 1011 & 5 \\
\hline C & 94 & 69 & 755 & 1154 & 980 & 3 \\
\hline
\end{tabular}

maior proporção de argilominerais. Dentre os álcalis, o $\mathrm{MgO}$ é o que apresenta teores mais elevados, especialmente nos perfis $1 \mathrm{e}$ 7 (entre $0,51 \%$ e $1,59 \%$ ). $\mathrm{O} \mathrm{Na} 2 \mathrm{O}$ é o mais baixo nesses dois perfis, enquanto o $\mathrm{CaO}$ o é nos demais e o $\mathrm{K}_{2} \mathrm{O}$ acompanha o $\mathrm{MgO}$, mas com teores mais baixos. O valor máximo de $\mathrm{TiO}_{2}$ é $4,3 \%$ no solo do perfil 4, enquanto $\mathrm{P}_{2} \mathrm{O}_{5}$, em geral é inferior a $1 \%$, destacam-se somente nos perfis 6 e 7 , onde alcança quase $3 \%$ no solo. O carbono varia independente do horizonte, entre $0,15 \%$ e $8,8 \%$ (Tabela 1). Essas características químicas, especialmente os teores elevados em álcalis, $\mathrm{P}_{2} \mathrm{O}_{5}$ e carbono orgânico, diferenciam estes perfis daqueles desenvolvidos sobre a Formação Alter do Chão, a leste da área estudada, onde o processo laterítico foi responsável pela formação de Latossolos, Argissolos e Espodossolos (Costa, 1991; Truckenbrodt et al., 1991; Leal, 1996; Horbe et al., 2001; Horbe et al., 2004). A pouca variação no conteúdo dos óxidos maiores, exceto $\mathrm{Fe}_{2} \mathrm{O}_{3}$, que nos níveis de ironstone do saprólito alcança $36 \%$ e nas concreções do solo $9 \%$ (Tabela 1), demonstra que há grande homogeneidade química entre os horizontes de cada perfil, inclusive com semelhança entre os perfis 1 e 6 da Formação Solimões com o Neossolo (perfil 7).

Nos perfis 4 e 7, onde foram analisados $\mathrm{Al}, \mathrm{Na}, \mathrm{K}, \mathrm{Ca}, \mathrm{Mg}$ e $P$ na fase disponível (Tabela 2) e dos quais depende a fertilidade do solo, constata-se que há relação direta entre os conteúdos totais de $\mathrm{CaO}, \mathrm{MgO}, \mathrm{P}_{2} \mathrm{O}_{5}$ e, em parte, de $\mathrm{K}_{2} \mathrm{O}$, mais elevados, com os também elevados na fase disponível (Tabelas 1 e 2). O Na não apresenta essa correlação, enquanto para o Al ela é inversa, ou seja, os teores totais de $\mathrm{Al}_{2} \mathrm{O}_{3}$ são mais elevados no perfil 7, mas mais baixos na fase disponível, enquanto no perfil 4 ocorre o oposto. Há variaçōes irregulares ao longo dos perfis, especialmente de $\mathrm{K}$, que não se correlaciona com a composição total de $\mathrm{K}_{2} \mathrm{O}$. Isto pode ser conseqüência da partição desse elemento tanto na muscovita, mais resistente ao intemperismo, como na illita. Os conteúdos elevados de $\mathrm{Ca}, \mathrm{Mg}$ e $\mathrm{P}$ na fase disponível do perfil 7 sugerem maior proporção de argilominerais 2:1, que são, dentre os minerais presentes nos perfis, os que têm maior capacidade de adsorção nos seus espaços interplanares, enquanto a pequena variação no teor de $\mathrm{Na}$ disponível nos dois perfis reflete a similaridade no teor total desse elemento. $\mathrm{O} \mathrm{Al}$ disponível, mais elevado no perfil com álcalis mais baixos, reflete o seu enriquecimento residual, por este ser muito imóvel, e eleva a acidez do meio (Tabela 1 ).

\section{ELEMENTOS-TRAÇO}

Dos elementos analisados, As, Mo, Sb, Ag, B, Be, Bi, Cd, Sn e W apresentam teores próximos ou abaixo do limite de detecção e somente $\mathrm{Pb}$ está acima da média crustal. Os conteúdos de $\mathrm{Hg}$, $\mathrm{Co}, \mathrm{Li}, \mathrm{Y}$ e Zn variam em relação à média crustal (Tabela 3). Em todos os perfis os teores de elementos-traço variam pouco entre os horizontes, com oscilações mais acentuadas para o $\mathrm{Hg}$ (14 ppb a $161 \mathrm{ppb})$, com tendência dos teores acima de $100 \mathrm{ppb}$ estarem no solo, e para o Co (< 8 a 126 ppm), com conteúdos em geral maiores no saprólio (Tabela 3). A ausência de clara partição dos elementos segundo os horizontes reflete a fraca diferenciação mineralógica e química e o baixo enriquecimento em ferro, que éo principal carreador desses elementos no ambiente intempérico.

Os perfis 3, 4 e 5 apresentam as menores concentrações de elementos-traço, especialmente de $\mathrm{Ba}$ e $\mathrm{Zn}$; os perfis 1 e 7 exibem as maiores, com destaque para $\mathrm{Ba}, \mathrm{Co}, \mathrm{Li}, \mathrm{Ni}, \mathrm{Sr}$ (principalmente no perfil 7), $\mathrm{V}$ e $\mathrm{Zn}$; enquanto os perfis 2 e 6 têm teores intermediários. Deve-se ressaltar que o $\mathrm{Hg}$ é o único elemento cujos maiores teores (até $161 \mathrm{ppb}$ ) estão nos perfis com as menores concentrações de elementos-traço ( 2 a 6). Este fato corrobora os dados que indicam o $\mathrm{Hg}$ como mais elevado em perfis mais lixiviados (até $200 \mathrm{ppb}$ - Costa et al., 1999, Oliveira et al., 2000 $-258 \mathrm{ppb}$ ), onde tende a se combinar com os óxi-hidróxidos de ferro. Essa correlação com o ferro é observada nas amostras com os teores mais elevados de $\mathrm{Hg}$ (Tabelas 1 e 3), contudo, no contexto da todas as amostras analisadas, somente $\mathrm{Cu}$, As e Co tem correlação com o $\mathrm{Fe}_{2} \mathrm{O}_{3}(\mathrm{r}>0,7)$. Os demais elementos, que normalmente tem afinidade com o ferro, como o $\mathrm{Zn}, \mathrm{V}, \mathrm{Ni}$ e Pb, não apresentam correlação, provavelmente devido a estarem associados, também, com os argilominerais $2: 1$, como indica a correlação deles com o $\mathrm{Al}_{2} \mathrm{O}_{3}(\mathrm{r}>0,7)$. Considerando-se que os horizontes/perfis que apresentam maiores conteúdos em álcalis têm também os maiores conteúdos da maioria dos elementostraço, estes devem estar relacionados, principalmente, à presença de muscovita, illita e esmectita, que ocorrem em todos os perfis estudados.

\section{RESULTADOS E DISCUSSÃO}

Com base na análise estatística multivariada do tipo componente principal dos dados químicos (óxidos maiores e 
Tabela 3 - Concentração dos elementos traço nos perfis estudados em ppm exceto $\mathrm{Hg}$ em ppb.

\begin{tabular}{|c|c|c|c|c|c|c|c|c|c|c|c|c|c|c|c|c|}
\hline Horizonte & $\mathrm{Ba}$ & $\mathrm{V}$ & $\mathrm{Zr}$ & $\mathrm{Zn}$ & $\mathrm{Sr}$ & $\mathrm{Pb}$ & $\mathrm{Y}$ & $\mathrm{Cr}$ & $\mathrm{Ni}$ & Co & $\mathrm{Cu}$ & $\mathrm{Li}$ & Sc & Mo & As & $\mathrm{Hg}$ \\
\hline \multicolumn{17}{|c|}{ Perfil 1} \\
\hline Solo & 480 & 113 & 109 & 238 & 74 & 72 & 61 & 62 & 56 & 43 & 38 & 31 & 12 & 6,2 & 4 & 29 \\
\hline Mosqueado & 525 & 134 & 111 & 326 & 84 & 81 & 48 & 71 & 76 & 59 & 50 & 42 & 14 & 3,4 & 5 & 45 \\
\hline Mosqueado & 521 & 137 & 131 & 278 & 88 & 76 & 48 & 71 & 72 & 51 & 45 & 40 & 14 & 3,4 & 4 & 39 \\
\hline Saprólito & 425 & 138 & 111 & 309 & 81 & 80 & 32 & 71 & 72 & 42 & 53 & 37 & 14 & 4,5 & 4 & 42 \\
\hline Saprólito & 601 & 96 & 83 & 243 & 44 & 81 & 27 & 62 & 41 & 126 & 75 & 20 & 10 & 1,5 & 21 & 62 \\
\hline \multicolumn{17}{|c|}{ Perfil 2} \\
\hline Solo & 224 & 81 & 142 & 48 & 47 & 55 & 16 & 42 & 5,2 & 12 & 28 & 19 & 8,6 & $<3,0$ & 4 & 94 \\
\hline Solo & 270 & 92 & 127 & 68 & 62 & 58 & 13 & 47 & 6,7 & 12 & 29 & 20 & 8,6 & $<3,0$ & 6 & 120 \\
\hline Solo & 263 & 111 & 110 & 55 & 66 & 73 & 12 & 53 & 7,4 & 11 & 25 & 20 & 11 & $<3,0$ & 2 & 150 \\
\hline Mosqueado & 162 & 76 & 62 & 26 & 30 & 51 & 6,9 & 28 & 5,9 & $<8,0$ & 14 & 15 & 7,9 & 3,1 & 2 & 69 \\
\hline Mosqueado & 175 & 73 & 58 & 30 & 26 & 57 & 7,6 & 33 & 7,2 & $<8,0$ & 12 & 16 & 7,9 & 3,8 & 2 & 31 \\
\hline \multicolumn{17}{|c|}{ Perfil 3} \\
\hline Solo & 173 & 115 & 101 & 35 & 35 & 73 & 11 & 51 & 6,9 & 9,3 & 21 & 18 & 11 & 3,4 & 9 & 95 \\
\hline Solo & 184 & 95 & 89 & 33 & 32 & 68 & 11 & 39 & 7,7 & 8,5 & 19 & 17 & 8,6 & 4,8 & 3 & 57 \\
\hline Mosqueado & 226 & 97 & 90 & 38 & 34 & 75 & 24 & 43 & 7,9 & 9,4 & 22 & 22 & 11 & 4,5 & 4 & 23 \\
\hline Saprólito & 242 & 98 & 100 & 66 & 36 & 74 & 38 & 42 & 13 & 11 & 28 & 25 & 13 & 5,2 & 4 & 22 \\
\hline \multicolumn{17}{|c|}{ Perfil 4} \\
\hline Solo & 136 & 95 & 140 & 23 & 44 & 55 & 13 & 48 & 4,4 & 10 & 17 & 15 & 7,9 & 3,1 & 3 & 161 \\
\hline Solo & 161 & 97 & 115 & 27 & 34 & 67 & 10 & 50 & 5,8 & 8,9 & 19 & 17 & 9,3 & 5,5 & 4 & 117 \\
\hline Mosqueado & 202 & 95 & 113 & 25 & 35 & 66 & 12 & 46 & 6,7 & 9,6 & 16 & 18 & 8,6 & 4,5 & 2 & 59 \\
\hline Mosqueado & 195 & 98 & 78 & 33 & 33 & 67 & 10 & 42 & 8,1 & 8,8 & 18 & 17 & 10 & 4,5 & 3 & 49 \\
\hline Mosqueado & 182 & 74 & 58 & 34 & 23 & 56 & 7,6 & 30 & 7,3 & $<8,0$ & 13 & 14 & 7,1 & 3,1 & 2 & 28 \\
\hline Saprólito & 148 & 62 & 45 & 27 & 21 & 43 & 7,3 & 28 & 5,7 & $<8,0$ & 11 & 13 & 6,4 & $<3,0$ & 4 & 14 \\
\hline Saprólito & 241 & 139 & 102 & 51 & 38 & 93 & 15 & 54 & 9,6 & 15 & 23 & 20 & 13 & 5,9 & 1 & 22 \\
\hline \multicolumn{17}{|c|}{ Perfil 5} \\
\hline Solo & 135 & 93 & 99 & 21 & 34 & 62 & 9,3 & 44 & 7,7 & $<8,0$ & 15 & 16 & 9,3 & $<3,0$ & 4 & 124 \\
\hline Mosqueado & 134 & 69 & 88 & 22 & 24 & 40 & 7,4 & 31 & 7,2 & $<8,0$ & 12 & 13 & 5,7 & 3,1 & 1 & 67 \\
\hline Mosqueado & 178 & 105 & 96 & 35 & 36 & 68 & 10 & 49 & 9,7 & 9,4 & 17 & 19 & 11 & 4,1 & 2 & 115 \\
\hline Saprólito & 99 & 47 & 90 & 25 & 23 & 35 & 8,8 & 24 & 5,8 & $<8,0$ & 11 & 14 & 4,3 & $<3,0$ & 1 & 69 \\
\hline \multicolumn{17}{|c|}{ Perfil 6} \\
\hline Solo & 237 & 137 & 137 & 49 & 44 & 91 & 15 & 85 & 7,6 & 10 & 31 & 25 & 15 & 3,4 & 11 & 171 \\
\hline Solo & 298 & 122 & 141 & 37 & 49 & 94 & 20 & 62 & 8,6 & 13 & 25 & 29 & 14 & 3,8 & 4 & 40 \\
\hline Mosqueado & 283 & 120 & 110 & 60 & 46 & 94 & 30 & 55 & 15 & 13 & 30 & 32 & 15 & 4,1 & 4 & 24 \\
\hline Mosqueado & 300 & 122 & 117 & 78 & 49 & 105 & 45 & 64 & 18 & 14 & 29 & 35 & 15 & 6,2 & 2 & 31 \\
\hline Saprólito & NA & NA & NA & NA & NA & NA & NA & NA & NA & NA & NA & NA & NA & NA & NA & NA \\
\hline \multicolumn{17}{|c|}{ Perfil 7} \\
\hline$A$ & 524 & 114 & 95 & 115 & 206 & 71 & 114 & 54 & 26 & 23 & 44 & 40 & 13 & 3,8 & 8 & 59 \\
\hline A & 509 & 94 & 81 & 96 & 218 & 61 & 94 & 46 & 21 & 19 & 35 & 31 & 11 & $<3,0$ & 3 & 44 \\
\hline C & 537 & 131 & 100 & 119 & 134 & 89 & 131 & 63 & 24 & 22 & 40 & 49 & 14 & 3,1 & 4 & 69 \\
\hline C & 502 & 112 & 94 & 115 & 204 & 72 & 112 & 54 & 25 & 24 & 40 & 39 & 12 & 4,8 & 5 & 61 \\
\hline C & 357 & 148 & 101 & 66 & 74 & 85 & 148 & 65 & 15 & 15 & 25 & 38 & 12 & $<3,0$ & 5 & 67 \\
\hline Média crustal & 580 & 150 & 150 & 80 & 300 & 10 & 30 & 100 & 75 & 25 & 50 & 30 & 13 & 1,5 & 2 & 200 \\
\hline
\end{tabular}

$\mathrm{Sb}, \mathrm{Ag}<1, \mathrm{Cd}<3, \mathrm{~B}<10, \mathrm{Bi}, \mathrm{Sn}, \mathrm{W}<20 ; \mathrm{NA}-$ não analisado.

elementos-traço), os elementos que melhor definem as características dos perfis estudados são: $\mathrm{SiO}_{2}, \mathrm{MgO}, \mathrm{V}, \mathrm{Y}, \mathrm{Ba}, \mathrm{Co}$, $\mathrm{Cr}, \mathrm{Cu}, \mathrm{Li}, \mathrm{Ni}$, Sc e $\mathrm{Zn}$; todos apresentam fatores com carga superior a 0,7 sendo o do $\mathrm{SiO}_{2}$ negativo e o dos demais positivos. Com base nesses elementos foram definidos dois grupos de amostras, que integrados às análises granulométricas e mineralógicas, refletem dois tipos geoquímicos de perfis (Figura 4): A - Perfis 2, 3, 4 e 5: formam as colinas tabulares da Formação Solimôes, apresentam textura arenosa a areno-argilosa, tem teores relativamente mais altos de $\mathrm{SiO}_{2}$, em conseqüência da predominância de quartzo e caulinita, bem como conteúdos mais elevados de $\mathrm{Al}$ disponível e mais baixo em álcalis e elementos- traço. O Hg tem em média as maiores concentraçōes; B - Perfis 1, 6e 7: os dois primeiros perfis formam também as colinas tabulares da Formação Solimões e o último o Neossolo da várzea do rio Solimōes. Apresentam textura mais pelítica, são geoquimicamente mais heterogêneos que o grupo anterior e se caracterizam por conteúdos mais elevados de esmectita, illita, $\mathrm{Al}_{2} \mathrm{O}_{3}$ e álcalis, especialmente de $\mathrm{MgO}$, e $\mathrm{P}_{2} \mathrm{O}_{5}$ e, conseqüentemente, são mais férteis. Contém, também, as maiores concentraçōes de elementostraço, especialmente de $\mathrm{Ba}, \mathrm{Cu}, \mathrm{Li}, \mathrm{Ni}, \mathrm{Pb}, \mathrm{Sr}, \mathrm{V}, \mathrm{Y}$ e Zn.

As características desses dois grupos indicam que os perfis do grupo A são os mais lixiviados e/ou formados, provavelmente, a partir de fácies, mais arenosos, pobres em álcalis e em elementos- 


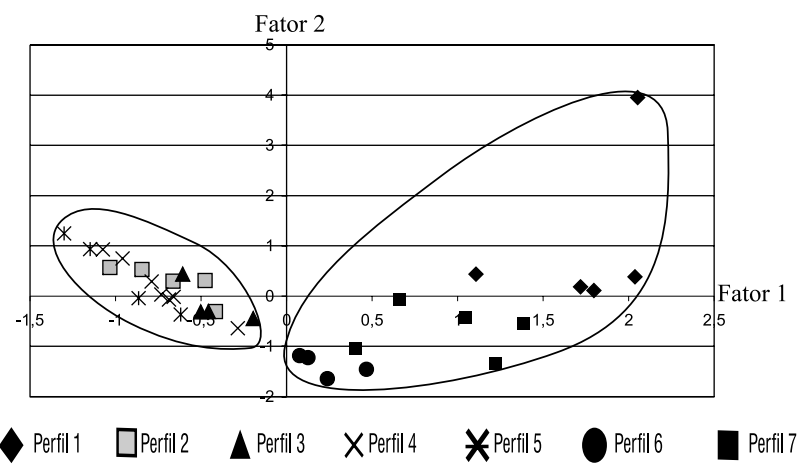

Figura 4 - Distribuição das amostras segundo os fatores 1 e 2 obtidos por análise de componentes principais.

traço; enquanto que os perfis 1 e 6 do grupo $B$ são mais pelíticos e com maior concentração de álcalis e elementos-traços e, portanto, com menor grau de lixiviação o que sugere também, origem a partir de fácies argilosos da Formação Solimōes. A semelhança geoquímica entre o perfil desenvolvido sobre o sedimento quaternário (perfil 7) com os perfis 1 e 6, sobre a Formação Solimōes, sugere que não há variaçōes químicas acentuadas entre os dois sedimentos, o que indica que o sedimento quaternário pode ter forte contribuição do material retrabalhado mais antigo.

A ausência de interestratificados illita-esmectita, clinocloro, sepiolita e clorita-vermiculita no saprólito, mosqueado e solo nos perfis sobre a Formação Solimões indica que durante a sua evolução houve diminuição na diversidade mineralógica. Contudo, a preservação de muscovita, esmectita e illita, as concentraçōes mais elevadas em álcalis, $\mathrm{Ba}, \mathrm{Cu}, \mathrm{Li}, \mathrm{Ni}, \mathrm{Pb}, \mathrm{Sr}, \mathrm{V}$, $\mathrm{Ye} \mathrm{Zn}$ incomum nos solos e perfis lateríticos desenvolvidos sobre rochas sedimentares mais antigas a leste (Costa, 1991; Truckenbrodt et al., 1991; Horbe \& Costa, 1997; Fernandes Filho et al., 1996; Leal 1996; Horbe et al., 2001; Horbe et al.; 2004) e a semelhança com o perfil 7 sobre o sedimento quaternário, é indicativa de que são pouco evoluídos, face a idade miocena da Formação Solimōes e ao clima atual quente e chuvoso da região de Coari $(2300 \mathrm{~mm} / \mathrm{ano})$, que promove intensa lixiviação. Portanto, os perfis 1 a 6 sobre a Formação Solimôes estão em desequilíbrio com o ambiente laterítico reinante na Amazônia nos últimos 60-70 milhôes de anos, por serem derivados de sedimentos com exposição recente ao ambiente laterítico da Amazônia. Essas características indicam que a exposição e o intemperismo dessa unidade deram-se, provavelmente durante o período Quaternário, mesma época de formação do perfil 7 .

\section{CONCLUSÕES}

A Formação Solimōes e os sedimentos do Quaternário, com os seus respectivos produtos intempéricos, formam as escarpas dos rios da região centro-leste do Amazonas. Nos perfis sobre a Formação Solimôes foram identificados, de baixo para cima, os horizontes saprolítico, mosqueado e solo, enquanto os gerados sobre o Quaternário são bem menos desenvolvidos, correlatos a Neossolos e constituídos dos horizontes $\mathrm{C}$ e A. A fração pelítica é a predominante nos perfis, seguida de areia muito fina a fina. Os minerais predominantes são quartzo e caulinita, ocorrendo subordinadamente hematita, goethita, muscovita, illita e esmectita em todos os perfis e horizontes. Interestratificados illitaesmectita, clinocloro, sepiolita e clorita-vermiculita estão restritos aos sedimentos da Formação Solimões. A composição química e a concentração dos elementos-traço permitiram definir dois grupos de perfis: A- perfis 1, 6 e 7, são mais argilosos, apresentam maiores concentrações em esmectita, illita, $\mathrm{Al}_{2} \mathrm{O}_{3}$ e álcalis, especialmente de $\mathrm{MgO}$ e $\mathrm{P}_{2} \mathrm{O}_{5}$ e, conseqüentemente, são mais férteis e contém maiores concentraçōes de elementos-traço, especialmente de $\mathrm{Ba}, \mathrm{Co}, \mathrm{Li}, \mathrm{Ni}, \mathrm{Pb}, \mathrm{Sr}, \mathrm{V}, \mathrm{Ye} \mathrm{Zn}$; B-perfis 2, 3, 4 e 5 , são mais lixiviados e/ou, formados, provavelmente, a partir de fácies mais arenosos pobres em álcalis e em elementos-traço. A semelhança geoquímica entre o perfil sobre o sedimento quaternário e parte dos perfis sobre a Formação Solimões sugere que o primeiro pode ser produto do retrabalhamento do sedimento mais antigo. A outra possibilidade para a semelhança mineralógica e química entre os perfis desenvolvidos sobre esses sedimentos, é que a mesma fonte do material. Contudo, a estratigrafia e a faciologia da Formação Solimões indicam que a fonte desta estaria a leste do Arco de Purus (Nogueira et al., 2003), enquanto os sedimentos quaternários estariam relacionados tanto aos Andes como também ao próprio trabalho dos sedimentos mais antigos próximos a calha do Solimões. A variação entre os grupos $\mathrm{A}$ e B sugere formação a partir de fácies sedimentares distintas, mais arenosas para o primeiro e mais pelítica para o segundo. Outra característica dos perfis estudados, especialmente aqueles sobre a Formação Solimôes, é a sua evolução pouco acentuada em relação aos perfis lateríticos localizados a leste da região, e seu desequilíbrio em relação ao clima atual quente e chuvoso da regiáo de Coari $\left(2.300 \mathrm{~mm} \cdot \mathrm{ano}^{-1}\right)$.

\section{AGRADECIMENTOS}

Os autores agradecem a Petrobrás, ao $\mathrm{CNPq}$ programa CTPETRO-CNPq processo no. 460223/01-1 e a CAPES, pelo apoio financeiro e pela concessão de bolsas de mestrado e pesquisa, e ao Instituto Evandro Chagas, pelas análises de mercúrio. Também aos revisores e ao editor da Acta Amazônica, pelas correçōes e sugestōes.

\section{BIBLIOGRAFIA CITADA}

Costa, M.L. 1991 Aspectos geológicos dos lateritos da Amazônia. Revista Brasileira Geologia, 21:146 160.

Costa, M.L.; Angélica, R.S.; Costa, N.C. 1999. The geochemical association $\mathrm{Au}-\mathrm{As}-\mathrm{B}-\mathrm{W}-\mathrm{Cu}-\mathrm{Sn}$ in latosol, colluvium, lateritic iron crust and gossan in Carajás, Brazil: its importance for identification of primary ore. Journal Geochemical Exploration, 67: 33-49. 
Fernandes Filho, L.A.; Costa, M.L.; Costa, J.B.S. 1996. Registros neotectônicos nos lateritos de Manaus. Geociências, 16: 9-33.

Hooghiemstra, H.; Hammen, T.V. 1998. Neogene and Quarternary development of the neotropical rain forest: the forest refugia hypothesis, and literature overview. Earth-Science Reviews, 44:147-183.

Horbe, A.M.C.; Costa, M.L. 1997. Solos gerados a partir do intemperismo de crostas lateríticas sílicoferruginosas. Acta Amazonica, 27: 241-256.

Horbe, A.M.C.; Nogueira, A.C.R.; Horbe, M.A.; Costa, M.L.; Suguio, K. 2001. A lateritização na gênese das superfícies de aplanamento da região de Presidente Figueiredo-Balbina, nordeste do Amazonas. In: Costa, M.L. \& Angélica, R. S.(org.) Contribuiçóes a Geologia da Amazônia. Vol 2. Sociedade Brasileira de Geologia - Núcleo Norte, Belém, Pará. p.148-176.

Horbe, A.M.C.; Horbe, M.A.; Suguio, K. 2004. Tropical Spodosols in northeastern Amazonas State, Brasil. Geoderma, 119: 55-68.

Horbe, A.M.C.; Nogueira, A.C.R.; Rozo, J.M.G. 2005. Evidências de dois episódios de lateritização na região de Novo Remanso AM. Congresso Brasileiro de Geologia, João Pessoa. Em CDRom.

Leal, P.C. 1996. Caracterização e interpretaçōes genéticas de alguns solos da região de Manaus - AM. Dissertação de Mestrado. Universidade Federal de Pernambuco. Recife, PE. 109pp.

Konhauser, K.O.; Fyfe, W.S.; Kronberg, B.I., 1994, Multi-element chemistry of some Amazonian waters and soils. Chemical Geology, 111: 155-175.

Kronberg, B.I.; Fralick, P.W.; Benchimol, R.E. 1998. Late Quaternary sedimentation and palaeohydrology in the Acre foreland basin, SW Amazonia. Basin Research, 10: 311-323.
Maia, R.G.N.; Godoy, H.K.; Yamaguti, H.S.; Moura, P.A.; Costa, F.S.F; Holanda, M.A.; Costa, J.A. 1977. Projeto carvão no Alto Solimões. Relatório final. Manaus, DNPM/CPRM, $11 \mathrm{v}$.

Nogueira, A.C.R.; Arai. M; Horbe, A.M.C. Horbe, M.A. Silveira, R.R.; Silva, J.J.; Motta, M. 2003. A influência marinha nos depósitos da Formação Solimões na região de Coari (AM): registro da transgressão miocênica na Amazônia Ocidental. In: SBG/Núcleo norte, 8. Simp. Geol. Amaz., Manaus. Resumos Expandidos. Cd Rom.

Oliveira, S.M.B.; Melfi, A.J.; Forstier, A.C.; Favero, D.I.T.; Boulet, R. 1999. O papel dos solos amazônicos como reservatórios de mercúrio. In: Cong. Bras. de Geoq. dos Países de Lingua Portuguesa, 5. e Congr. Bras. de Geoq., 7. Porto Seguro, Resumos Expandidos p. $146-149$.

Radambrasil 1978. Folha SA. 20 Manaus: geologia, geomorfologia, pedologia, vegetação e uso potencial da terra. Rio de Janeiro, 1978. (Levantamento de Recursos Naturais, 18). 456p.

Rossetti, D.F.; Toledo, P.M.; Góes, A.M. 2005. New geological framework for Western Amazonia (Brazil) and implications for biogeography and evolution. Quaternary Research, 64: 279-280

Rosolen, V.; Lamotte, M.; Boulet, R.; Trichet, J.; Rouer, O.; Merfi, A.J. 2002. Genesis of the mottled horizon by Fe-depletion within a lateritic cover in the Amazon Basin. C.R. Geoscience, 334:187195.

Truckenbrodt, W.; Kotschoubey, B.; Schellmann, W. 1991 Composition and origin of the clay cover on north Brazilian laterites. Geologische Rundschau, 80: 591610.

Recebido em 06/10/2006

Aceito em 02/02/2007 
